\title{
Users' Perceptions, Attitudes and Continuance Intentions of Facebook: Insights from Pakistan
}

\author{
Dr. Ijaz A. Qureshi ${ }^{1}$, Imran A. Mir ${ }^{2}$ \\ JFK Institute of Technology and Management, Pakistan)
}

\begin{abstract}
Uses of social network sites (SNSs) are diversifying in an astounding fashion. SNSS (e.g. Facebook) can no more be seen as online platforms solely for socializing. This study examines the Facebook users' perceptions, attitudes and continuance intentions of the site (Facebook). To meet this objective data was collected from a purposive sample of 211 respondents who have been using Facebook for more than one year. Results show that users perceive Facebook as a useful source of information and entertainment. Furthermore, results reveal that users perceive Facebook as a platform for self-expression, building social capital and meeting offline and new contacts. Perceptions about Facebook as a source of information and a platform of self-expression have a positive effect on users' continuance intentions of the site (Facebook). Attitudes toward the Facebook mediate the relationship between users 'perceptions of the site as a source of entertainment and a platform of building social capital and their continuance intentions of the site.
\end{abstract}

Keywords: Perceptions, Attitudes, Continuance Intentions

\section{INTRODUCTION}

Uses of social network sites (SNSs) are diversifying in a surprising way. SNSs (e.g. Facebook) can no more be seen as online platforms exclusively for socializing (Hjorth and Arnold, 2011). SNSs are rapidly evolving as platforms for civic and political participation (Bennett, 2008; Bennett and Wells 2009) and selfexpression (Pempek, Yermolayeva, and Calvert, 2009). Facebook has become a leading source of information and enjoyment. Facebook is the most frequently visited SNS in Pakistan. The current registered users of Facebook in Pakistan are over 6.5 million and this figure is estimated to be more than 10 million by June 2013 (Bsolutions.pk).Today people are seeking the ways how to utilize SNSs (e.g. Facebook) to engage in political discussions and articulate their views about the valued issues (Kushin and Kitchener, 2009). Most of the previous studies examined the user motivations to participate in SNSs. Various past studies (e.g. Ellison, Steinfield, and Lampe, 2007; Lampe, Vitak, Ellison, 2013; Park, Kee, and Valenzuela, 2009) focused on the Facebook use, formation and maintenance of social capital. Many studies (e.g. Subrahmanyama, Reich, Waechter, Espinoza, 2008) examined the user activities on SNSs. Few studies (e.g. Zhang, Johnson, Seltzer and Bichard, 2009) studied the role of SNSs in engaging the people in civic management and politics. However, previous studied did not examine the user perceptions of the Facebook as a platform of building social capital, civic and political participation and self-expression. Furthermore, previous studies focused on the users' information and entertainment motivations to use Facebook. However, least studies examined user perceptions of the Facebook as a source of information and entertainment. None of the past studies examined these five user perceptions of Facebook in a single study. Current study fills this gap in literature by identifying user perceptions of the Facebook and their effect on user attitudes and continuance intentions of the Facebook in a South Asian Context.

\section{LITERATURE REVIEW}

Facebook facilitates its users in building social capital. Social capital refers to the resources which people accumulate by creating and maintaining relationships with other people in different social settings (Coleman, 1988; Ozmete, 2011). Generally two forms of social capital (i.e. bonding and bridging capital) are identified to exist. Bonding capital is related to tightly knitted ties while bridging capital is associated with weaker or loosely knitted ties. Tightly knitted ties (e.g. friends, family members) are source of emotional support while loosely knitted ties can be a valuable source of novel information (Putnam, 2000). Tightly knitted ties are the stronger relationships with whom an individual frequently interacts (Ellison et al., 2007). In case of loosely knitted ties, interactions and connections among individuals are non-intimate and infrequent. Various studies (e.g. Ellison et al., 2007; Pempek et al., 2009) identified that Facebook facilitates people to maintain relationships with existing offline contacts and helps them to develop new relationships. SNSs (e.g. Facebook) strengthen existing connections and communities by keeping its users regularly updated about activities and affairs of their contacts (Park et al., 2009). Facebook assists its users to communicate with their family members, friends, professional contacts. It also aids them in connecting and interacting with new contacts (strangers) who share similar interests (Brady, 2013). 
SNSs users perceive Facebook as a useful source of information. Perceived infromativeness of SNSs affect users' SNSs usage behavior (Zhang, 2011). Users find Facebook more useful and have made it a part of their daily routine to a considerable extent. Users indicate that they receive positive and useful information from Facebook (Lampe, Ellison, and Steinfield, 2008). Information receiving and Facebook adoption are significantly related (Nasri and Charfeddine, 2012). Individuals use internet and internet based applications (e.g. SNSs) to find problem-specific and general information (Savolainen, 2007). Information seeking is one of the important factors motivation people to use SNSs (Park et al., 2009). Lampe, Vitak, Gray, and Ellison (2012) found significant relationship between users' perceptions of Facebook as an appropriate source of information and information seeking behavior.

SNSs users perceive Facebook an important source of entertainment (boyd, 2007). SNSs (e.g. Facebook) are entertaining and exciting. Perceptions of SNSs as entertaining and exciting depend on the age of SNSs users (Jain and Sadriwala, 2013). Perceived enjoyment has a significant effect on usefulness of Facebook (Nasri and Charfeddine, 2012). In China GONG,( 2012) found that perceived enjoyment has a significant influence on SNSs use. SNSs provide a lot of enjoyment to its users and create a sense of connectedness among users. People use Facebook to entertain themselves or to feel pleasure (Dhaha and Igale, 2013). Entertainment is an important factor motivating students to use Facebook (Park et al., 2009). Entertainment is a positive predictor of the amount time which people spend on Facebook (Dhaha and Igale, 2013).

SNSs are rapidly emerging as platforms for civic management and political participation (Bennett 2008; Bennett and Wells 2009). SNSs can no more be inferred as means solely for socializing. Today people are seeking the ways how to utilize social media (e.g. SNSs) to engage in poltical discussions and articulate their views about the valued issues (Kushin and Kitchener, 2009). People especially youth are freely sharing their feelings, views and thoughts on different social issues and problems. Youth are not just sharing their thoughts but raising their voices against social evils such as corruption, human rights violation etc. on Facebook (Jain, Gupta, and Anand, 2012. Skoric and Kwan (2011) stated that civic participation and poltical discussion are increasingly taking place on Facebook. Skoric and Kwan also found that intensity of using Facebook and online and offline political participation are correlated.

Facebook provides novel ways of interaction and self-expression to its users (Pempek et al., 2009). Oxford Advanced Learners'Dictionary (2013) defines self-expression as "the expression of thoughts or feelings, especially through activities such as writing, painting, dancing, etc". Young users participate in Facebook for diverse reasons and one of them is self-expression (boyd, 2007). Students engage in SNSs as they perceive these sites as a mean to express themselves. Users express themselves by writing on the walls of the Facebook and by uploading and sharing the photos with other users on Facebook. Facebook users express their various emotions with other users through status up dates. Usually users express their feeling on Facebook through quotes, poetry and images (Pempek et al., 2009).

\section{PROPOSED MODEL AND HYPOTHESES}

Understanding perceptions is of vital importance since they affect attitudes (Moorman, Blakely, and Niehoff, 1998). Schiffman and Kanuk (2007, p.172) defined perceptions "as the process by which an individual selects, organize and interprets stimuli into a meaningful and coherent picture of the world". In simple words, perceptions can be described as how people see the world around them (Schiffman and Kanuk, 2007). How an individual sees a phenomenon or object is known as social perceptions. An individual's perception of an object is the function of his/her past experience with that object (Schiff, 1970). This study postulates that user' perceptions of Facebook as a platform for building social capital, civic and political participation and selfexpression have a positive effect on their attitudes toward the site (Facebook). Similarly, these factors are assumed to have a positive effect on users' continuance intentions of the Facebook (See Fig. 1). Lampe et al.

(2013) found that heavy Facebook users reported higher perceived bridging and bonding social capital. Individuals' decision to engage in Facebook depends on their perceptions of how widely Facebook is used by their offline contacts. Several studies (e.g. Pempek et al., 2009) identified that Facebook facilitates people to maintain relationships with existing offline contacts and helps them to develop new relationships. Some studies (e.g. Jain et al., 2012) found that SNSs particularly Facebook is acting as "phenomenal medium for view mobilization". People especially youth are freely sharing their feelings, views and thoughts on different social issues and problems on Facebook. In other words, Facebook facilitates its users in civic or social participation. Skoric and Kwan (2011) stated that civic participation and political discussion are increasingly taking place on Facebook. Williams and Merten (2008) found that several students engage in SNSs (e.g. in Facebook) as they perceive these sites as a mean of self-expression. Furthermore, this study postulates that user perceptions of Facebook as a source of information and entertainment have a positive effect on their attitudes toward the site (Facebook). Similarly, these factors are supposed to affect users' continuance intentions of the Facebook positively (See Fig. 1). Lampe et al. (2012) found significant relationship between users' perceptions of the Facebook as an appropriate source of information and information seeking behavior. Perceived infromativeness 
of SNSs affect users' SNSs usage behavior (Zhang, 2011). Similarly, boyd (2007) found that SNSs users perceive Facebook an important source of entertainment. Entertainment is the hedonic pleasure or enjoyment which users receive from Facebook. User perceptions of the Facebook as a source of entertainment affect their Facebook usage behavior (Dhaha and Igale, 2013).

The postulation that user perceptions of the Facebook have a positive effect their attitudes toward the site (Facebook) is consistent with Moorman et al. (1998) and Schiff (1970) who stated that perceptions impact attitudes. Fishbein and Ajzen (1975) defined "attitude as a person's favorable or unfavorable feelings toward an object". Lampe et al. (2008) found that Facebook users hold the positive attitudes toward the sites. Facebook has become the part of everyday routine of its users. Gangadharbatla (2008) found that user' attitudes toward SNS (Facebook) work as a mediator between their perceptions and behaviors. Therefore, this study proposes that user attitudes toward the Facebook and their intentions to continue using the Facebook in future are positively associated (See Fig. 1). Intentions are stronger predictors of actual behavior (Ajzen, 1991). Therefore, understanding users' continuance intentions of the Facebook is of vital importance. "Intentions are assumed to capture the motivational factors that influence a behavior; they are indications of how hard people are willing to try, of how much of an effort they are planning to exert, in order to perform the behavior (Ajzen,1991, p.181). In Fig. 1 FB symbolizes Facebook.

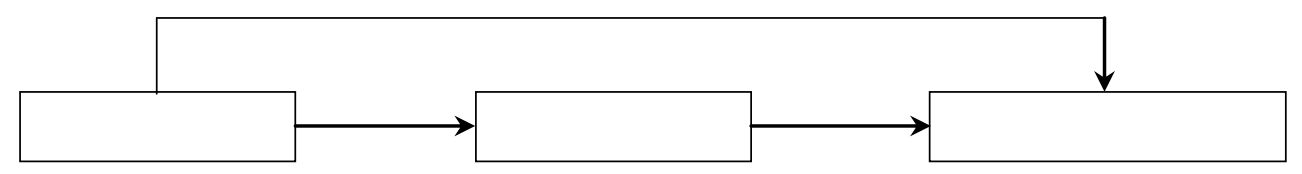

Fig1. Proposed Model verification:

Based on the literature and above proposed model following hypotheses are set forth for empirical

H1. Users 'perceptions of the Facebook have a positive effect on their attitudes toward the site (Facebook).

H2. Users 'perceptions of the Facebook have a positive effect on their continuance intentions of the site (Facebook).

H3. Users' attitudes toward the Facebook and their continuance intentions of the site are positively associated.

\section{METHODOLOGY}

Data was collected from a purposive sample of 211 university students (31\% females and $69 \%$ male) at Islamabad who have been using Facebook for more than one year. $6.6 \%$ respondents were under 20 of age, $91.9 \%$ were between $20-29, .9 \%$ were between $30-39,5 \%$ were 40 and above. $24.7 \%$ respondents were enrolled in undergraduate programs while $75.3 \%$ were enrolled in graduate programs.

To operationalize user perceptions of the Facebook measures were adapted from Husfeldt et al. (2005), Jung et al. (2013), Kyle et al. (2007), Lampe et al. (2008), Lee et al., (1999), Mir (2012), Park et al. (2009) and Skoric and Kwan (2011). All the constructs were measured on a 5-point likert scale ranging from 1 (strongly disagree) to 5 (strongly agree).

Principle component analysis (PCA) with varimax rotation was conducted on 51 measurement items to screen them and identify the underlying dimensions of use perceptions of the Facebook. The PCA produced five dimensions (factors) underlying user perceptions of the Facebook. Information (F1) with eigen value 7.359.

Contacts (F2) with eigen value 1.717. Self-expression (F3) with eigen value1.459. Entertainment (F4) with eigen value 1.363. Social Capital (F5) with eigen value 1.023. The rule of minimum eigen value of 1.0 was applied. Items with factor loadings and commonalities more than .50 were retained and rests of them were deleted. Table 1 show dimensions( factors) of user perceptions of the Facebook, their factor validity, reliability, Percentage of total variance, Kaiser Kaiser-Meyer-Olkin (KMO) index, and Bartlett's Test of Sphericity.

A confirmatory factor analysis (CFA) was performed to measure the goodness-fit of the measurement model for perception factors. Amos version 16 was used for the structural modelling analysis. The model provides the bad fit to the data with a Chi-square $(\chi 2)$ value 176.139 , d.f. $=80, \mathrm{P}=.000(\mathrm{p}<.05)$. However, ratio of $\chi 2 /$ d.f. $=2.202$ is satisfactory. The ratio of " $\chi 2 /$ d.f. $<5$ " is considered reasonable to accept the model. In addition to $\chi^{2}$ and $\chi^{2}$ d.f. Goodness of Fit Index (GFI), Incremental Fit Index (IFI), Comparative Fit Index (CFI), Normed Fit Index (NFI), Tucker-Lewis Index (TLI), and Root Mean Square Error of Approximation (RMSEA) indices were used to evaluate the goodness fit of the measurement model for perception factors.

Conventional cut-off criteria of model fit (See Bentler, 1990) were applied to judge the goodness-fit of the model for perception factors on these indices. According to conventional cut-off criteria, the values of GFI, IFI, CFI, NFI and TLI should be equal or greater than 0.90 while the value of RMSEA should be less than 0.08 . This study revealed the following values of these indices: $\mathrm{GFI}=.914, \mathrm{IFI}=.911, \mathrm{CFI}=.909, \mathrm{NFI}=950$, 
TLI $=.900$ and RMSEA $=.076$. Based on the conventional cut-off criteria of model fit these results indicate that the measurement model for perception factors fit the sample satisfactorily. Fig 2 shows the R2, estimates of covariance and standardized estimates for the items of the factors underlying users' perceptions of the Facebook.

Table 1. Summary of PCA Results

\begin{tabular}{|c|c|c|c|c|c|c|}
\hline User Perceptions of Facebook & $F 1$ & $F 2$ & $F 3$ & F4 & F5 & Reliability \\
\hline Facebook helps me to get information about off-campus events & .78 & & & & & $.76^{* *}$ \\
\hline Facebook helps me to learn about on-campus events & .75 & & & & & \\
\hline Facebook helps me to meet new people & & .79 & & & & $.60 *$ \\
\hline Facebook helps me to keep in touch with offline friends & & .80 & & & & \\
\hline Facebook helps me to share my feelings with my friends & & & .62 & & & \\
\hline Facebook is entertaining & & & & .74 & & $.77 * *$ \\
\hline Facebook is enjoyable & & & & .70 & & \\
\hline Facebook is fun to use & & & & .72 & & \\
\hline The people I interact with on Facebook would be good job references for me. & & & & & .73 & \\
\hline $\begin{array}{l}\text { The people I interact with on Facebook would share their important information with } \\
\text { me. }\end{array}$ & & & & & .78 & \\
\hline Percentage of total variance 61.527 & & & & & & 61.527 \\
\hline Kaiser-Meyer-Olkin Measure of Sampling Adequacy Index & & & & & & .862 \\
\hline Bartlett's Test of Sphericity & & & & & & .000 (sig.) \\
\hline
\end{tabular}

Note: Cronbach's Alpha (**) \& Guttman's Split-Half Coefficient (*)

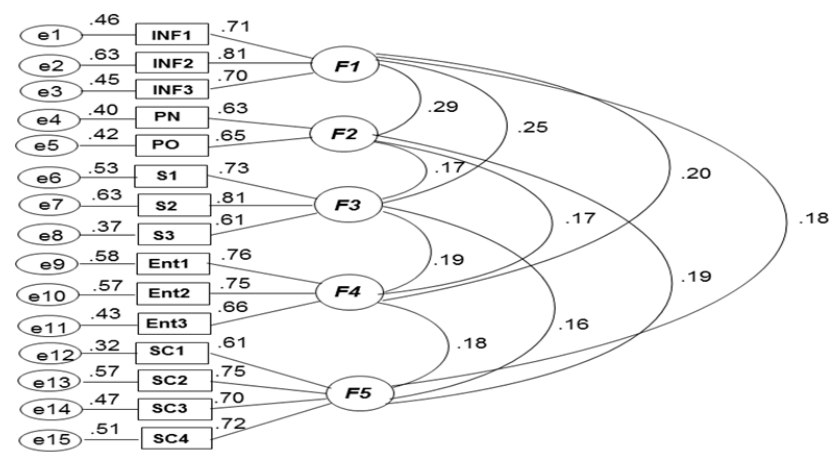

\subsection{Attitudes and continuance intentions}

User attitudes toward the Facebook were measured on a five item measurement scale. Three items (i.e. Overall, I consider Facebook a good thing, I would describe my overall attitude towards Facebook very favorably, My general opinion about Facebook is favorable) were adapted from Mir (2012). Two items (Facebook is part of my everyday activity, Facebook has become part of my daily routine) were adapted from Lampe et al. (2008). The overall reliability of these five items was .739. Two items (i.e. I will continue using Facebook in future and I plan to use the Facebook in the future) were adapted from Lee and Kwon, (2010) to measure the users' continuance intentions of Facebook. Guttman's Split-Half Coefficient of these items was .734. These constructs were measured on a 5-point likert scale ranging from 1 (strongly disagree) to 5 (strongly agree).

\subsection{Model fit}

\section{Results}

The model presents the good fit to the data with a chi-square $(\chi 2)$ value 5.750 , d.f. $=5, \mathrm{P}=.331(\mathrm{p}>.05)$, $\chi 2 /$ d.f. $=1.150$. Besides $\chi 2$ and $\chi 2 /$ d.f. six indices, Goodness of Fit Index (GFI), Incremental Fit Index (IFI), Comparative Fit Index (CFI), Normed Fit Index (NFI), Tucker-Lewis Index (TLI), and Root Mean Square Error of Approximation (RMSEA) were used to examine the model fit. An optimal Cut-Off criterion (see Sivo et al., 
2006) was used to examine the goodness fit of the model on these indices (see Table 2). The model presents good fit on these indices.

Table 2 Model Fit Indices

\begin{tabular}{|c|c|c|c|c|c|c|}
\hline Indices & GFI & IFI & CFI & NFI & TLI & RMSEA \\
\hline Model values & .992 & .998 & .998 & .984 & .991 & .027 \\
\hline Optimal Cut-Off Values & $>.95$ & $>.95$ & $>.95$ & $>.95$ & $>.95$ & $<.05$ \\
\hline
\end{tabular}

\subsection{Structural model and hypotheses testing}

This study found five dimensions underlying users 'perceptions about Facebook. User perceptions of Facebook as a source of entertainment and a platform of building social capital accounts 18 percent variation in user attitudes toward the Facebook as $\mathrm{R}^{2}=.18$. Similarly, User perceptions of Facebook as a source of information and a platform for meeting new and socially known contacts and self-expression accounts 28 percent variation in their intention to continue using Facebook as $\mathrm{R}^{2}=.28$ (See Fig. 3). Only entertainment and social capital has a positive effect on user attitudes toward the Facebook. Therefore, H1 can be partially accepted (See Table 3). Similarly, only information and self-expression have a positive effect on users' continuance intentions of Facebook. Conversely, meeting new and social known contacts has a negative effect on users' continuance intentions of Facebook. Therefore, H2 can be partially accepted (See Table 3). Results show a significantly positive association between user attitudes toward the Facebook and their continuance intentions (See Table 3). Therefore, H3 is accepted. Fig. 3 presents the structural model graphically.

Table 3 Regressions Weights of Structural Model

\begin{tabular}{|c|c|c|c|c|c|}
\hline \multicolumn{2}{|c|}{ Regression Paths } & \multirow{2}{*}{\begin{tabular}{c|} 
B \\
.194
\end{tabular}} & \multirow{2}{*}{$\begin{array}{c}\text { S.E. } \\
.058\end{array}$} & \multirow{2}{*}{$\begin{array}{c}\text { C.R. } \\
2.781\end{array}$} & \multirow{2}{*}{$\begin{array}{c}\mathbf{P} \\
.005\end{array}$} \\
\hline Entertainment & $\rightarrow \quad$ Attitude & & & & \\
\hline Social Capital & $\longrightarrow$ Attitude & .304 & .064 & 4.361 & $* * *$ \\
\hline Information & Continuance Intentions & .151 & .085 & 2.128 & .033 \\
\hline Self-expression & $\rightarrow \quad$ Continuance Intentions & .313 & .084 & 4.586 & $* * *$ \\
\hline Attitude & $\rightarrow$ Continuance Intentions & .301 & .096 & 4.966 & $* * *$ \\
\hline Contacts & $\longrightarrow$ Continuance Intentions & -.103 & .075 & -1.547 & .122 \\
\hline
\end{tabular}

Note: ${ }^{* p}<.05, * * p<.01, * * * p<.001$

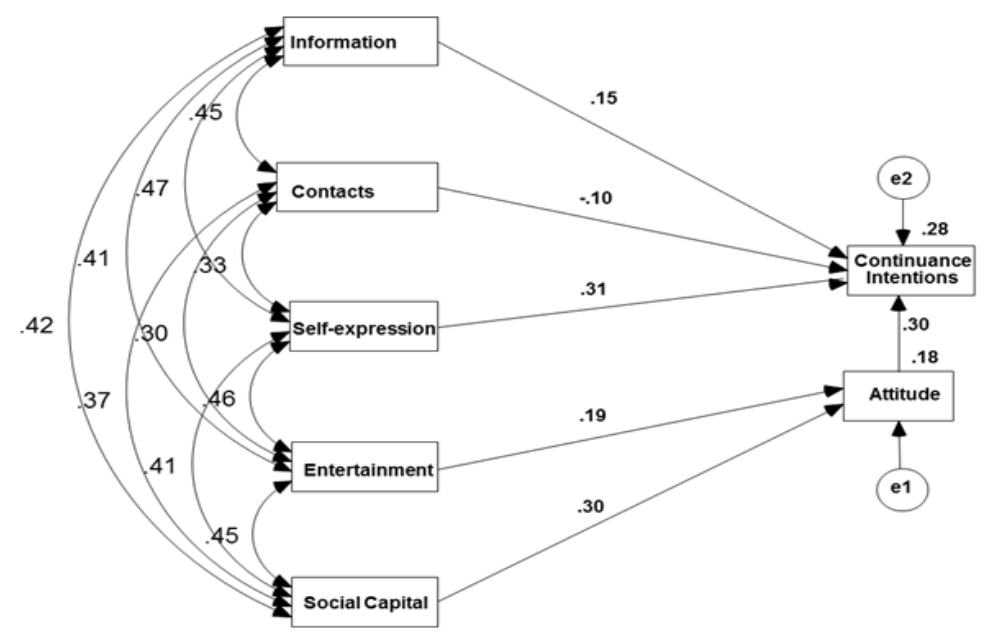

IV. Discussion

Uses of SNSs are diversifying in a surprising way. SNSs (e.g. Facebook) can more be seen as online platforms solely for socializing (Hjorth and Arnold, 2011). This study aimed to identify the Pakistani users' perceptions of the Facebook. Facebook is a most frequently visited SNS in Pakistan. This study identified five perceptions that Pakistani Facebook users hold about the site (Facebook). Those perceptions are Facebook as a source of information, entertainment and a platform of meeting offline and new contacts, self-expression and building social capital.

This study found that perceptions of the Facebook as a source of information and a platform of selfexpression have a positive effect on users' intentions to continue using Facebook in future. Past studies (e.g. Zhang, 2011) identified that SNSs users perceive Facebook as a useful source of information. Perceived infromativeness of SNSs affect users' SNSs usage behavior. Similarly, past studies (e.g. Williams and Merten, 
2008) found that students engage in SNSs (e.g. in Facebook) since they perceive these sites a mean to express themselves. Past studies (e.g. Lampe et al., 2008; Pempek et al., 2009; Subrahmanyama et al., 2008) found that people use SNSs (e.g. Facebook) to stay in touch with offline contacts (e.g. friends, colleagues etc.) and meet new contacts (strangers). This study came up with the same finding. However, meeting offline and new contacts on Facebook has a negative impact on the users' continuance intentions of the Facebook in Pakistan as far as the findings of this study are concerned.

Moorman et al. (1998) and Schiff (1970) stated that perceptions impact attitudes. This study found that perceptions of Facebook as a source of entertainment and a platform of building social capital has a positive impact on users' attitudes toward the site (Facebook). Boyd (2007) identified that SNSs users perceive Facebook an important source of entertainment. In China, Gong (2012) found that perceived enjoyment has a significant influence on SNSs use. Various past studies (e.g. Ellison et al., 2007; Pempek et al., 2009) identified that people use SNSs to build social capital. Nonetheless, past studies focused on the dimensionality of online social capital and least past studies examined its impact on user attitudes toward the site. Furthermore, this study found that user attitudes toward the Facebook and their continuance intentions of the site (Facebook) are positively associated. Gangadharbatla (2008) found that user' attitudes toward SNS (Facebook) work as a mediator between their perceptions and behaviors.

\section{Conclusion}

This study examined the Facebook users' perceptions about the site and the impact of those perceptions on their attitudes and continuance intentions of the site (Facebook). Results reveal that user perceptions of the Facebook as a source of information and a platform of self-expression have a positive effect on their continuance intentions of the Facebook. Nonetheless, statistically impact of self-expression is relatively stronger on users' continuance intentions of the Facebook. Furthermore, results show that user attitudes toward the Facebook mediate the relationship between user perceptions of the Facebook as a source of entertainment and a platform of building social capital and their continuance intentions of the site.

Most of the past studies analyzed user perceptions and attitudes toward the Facebook from Western contexts. This study provides Facebook users perceptual and attitudinal Insights from a South Asian Context. Since this study used purposive sampling for data collection, therefore its findings should be cautiously generalized. Future studies should use more robust sampling techniques to enhance the external validity of these findings.

\section{REFERENCES}

[1]. Ajzen. The theory of planned behavior. Organizational Behavior and Human Decision Processes. 50, 1991, $179-211$.

[2]. W.L. Bennett. Changing citizenship in the digital age. In civic life online: Learning how digital media can engage youth, W. L. Bennett, Ed. MIT Press, Cambridge, MA, 2008, 1-24,

[3]. W.L. Bennett and C. Wells. Civic engagement: Bridging differences to build a field of civic learning. International Journal of Learning and Media. 1(3), 2009, 1-10.

[4]. P.M. Bentler. Comparative fit indexes in structural models. Psychological Bulletin. 107(2), 1990, 238-246.

[5]. d. boyd. Why youth (heart) social network sites: The role of networked publics in teenage social life. In MacArthur Foundation Series on Digital Learning -Youth, Identity, and Digital Media Volume, D. Buckingham, Ed. MIT Press, Cambridge, MA, 2007.

[6]. E. Brady. Unique considerations in social network question asking by blind users. CSCW'13, February 23-27th, San Antonio, Texas, USA, 2013.

[7]. Bsolutions.pk.10 Million Pakistani users on Facebook by 2013. http://www.bsolutions.pk/10-million-pakistani-users-on-facebookby-2013-infographic.html.Accessed. Accessed on 7/4/2013.

[8]. J.S. Coleman. Social capital and the creation of human capital. The American Journal of Sociology. 94 (Supplement), 1988, S95S120.

[9]. S.S.Y. Dhaha and A.B. Igale. Facebook usage among Somali youth: A test of uses and gratifications approach. International Journal of Humanities and Social Science. 3(3), 2013, 299-313.

[10]. N.B. Ellison, C. Steinfield and C. Lampe. The benefits of Facebook friends: Social capital and college students' use of online social network sites. Journal of Computer-Mediated Communication. 12, 2007, 1143-1168.

[11]. M. Fishbein and I. Ajzen. Belief, attitude, Intention and Behavior: An introduction to theory and research. Addison-Wesley, Boston, 1975

[12]. H. Gangadharbatla. Facebook me: Collective self-esteem, need to belong and Internet self-efficacy as predictors of the igeneration's attitudes toward social networking sites. Journal of Interactive Advertising. 8(2), 2008, 5-15.

[13]. W. Gong. Factors influencing perceptions toward social networking websites in China. M. Strano, H. Hrachovec, F. Sudweeks and C. Ess. Eds. Proceedings cultural attitudes towards technology and communication, Murdoch University, Australia, $2012,420-429$.

[14]. L. Hjorth and M. Arnold. The personal and the political: social networking in Manila. International Journal of Learning and Media. 3 (1), 2011, 29-39.

[15]. M. R. Jain, P. Gupta and N. Anand. Impact of social networking sites in the changing mindset of youth on social issues: A study of Delhi-NCR youth. Journal of Arts, Science and Commerce. 3(2/2), 2012, 36-43.

[16]. D. Jain and F.F. Sadriwala. Perception towards entertainment value of users by social networking sites: An empirical study. Asia Pacific Journal of Marketing \& Management Review. 2(3), 2013, 1-12.

[17]. Y. Jung, R. Gray, C. Lampe and N.B. Ellison. Favors from Facebook friends: Unpacking dimensions of social capital. CHI, 13, April 27 - May 2, Paris, France, 2013.

[18]. M. J. Kushin and K. Kitchener. Getting political on social network sites: Exploring online political discourse on Facebook. In First Monday. 14(11-2), 2009. 
[19]. G. Kyle, J. Absher, W. Norman, W. Hammitt and L. Jodice. A modified involvement scale. Leisure Studies, 26 (4), $2007,399-427$.

[20]. C. Lampe, N.B. Ellison and C. Steinfield. Changes in use and perception of Facebook. CSCW 08, November 8-12, , San Diego, California,USA, 2008.

[21]. C. Lampe, J. Vitak, R. Gray and N.B. Ellison. Perceptions of Facebook's value as an information source. CHI, May 5-10, Austin, TX, USA, 2012.

[22]. C. Lampe, J. Vitak and N.B. Ellison. Users and Nonusers: Interactions between Levels of Facebook Adoption and Social Capital. CSCW'13, February 23-27, San Antonio, Texas, USA, 2013.

[23]. Y. Lee and O. Kwon. Gender differences in continuance intention of on-line shopping services. Asia Pacific Journal of Information Systems. 20 (3), 2010, 51-72.

[24]. S-J. Lee et al. Development of a Self-presentation Tactics Scale. Personality and Individual Differences, 26 (4), 1999, $701-722$.

[25]. I.A. Mir. Consumer attitudinal insights about social media advertising: A South Asian perspective. The Romanian Economic Journal. XV(45), 2012, 265-288.

[26]. R.H. Moorman, G.L. Blakely and B.P. Niehoff. Does perceived organizational support mediate the relationship between procedural justice and Organizational citizenship behaviour. Academy of Management Journal. 41(3), 1998, 351-357.

[27]. W. Nasri and L. Charfeddine. An exploration of facebook.com adoption in Tunisia using technology acceptance model (TAM) and theory of reasoned action (TRA). Interdisciplinary Journal of Contemporary Research in Business. 4(5), 2012, 948-968.

[28]. E. Ozmete. Understanding of social capital with ecosystem approach. International Journal of Academic Research. 3(3), 2011, 333339.

[29]. N. Park, K.F. Kee and S. Valenzuela. Being immersed in social networking environment: Facebook groups, uses and gratifications, and social outcomes. CyberPsychology and Behavior. 12(6), 2009, 729-733.

[30]. T.A. Pempek, Y.A. Yermolayeva and S.L. Calvert. College students' social networking experiences on Facebook. Journal of Applied Developmental Psychology. 30, 2009, 227-238

[31]. R.D. Putnam. Bowling Alone. Simon and Schuster, New York, 2000

[32]. R. Savolainen. Information source horizons and source preferences of environmental activists: a social phenomenological approach. Journal of the American Society for Information Science and Technology. 58(12), 2007, 1709-1719.

[33]. Oxford Advanced Learners' Dictionary. Self-expression. http://oald8.oxfordlearnersdictionaries.com/ dictionary/self-expression. Accessed on 3/16/2013.

[34]. L.G. Schiffman and L.L Kanuk. Consumer Behavior. 9th Ed. Prentice Hall, Upper Saddle River, New Jersey, 2007.

[35]. M.R. Schiff. Some theoretical aspects of attititudes and perceptions. Working Paper No. 15. University of Toronto, 1970.

[36]. A.S. Sivo, X. Fan, E.L. Witta and J.T. Willse. The search for "optimal" cutoff properties: Fit index criteria in structural equation modeling. The Journal of Experimental Education. 74(3), 2006, 267-288.

[37]. M.M. Skoric and G. Kwan. Do Facebook and video games promote political participation among youth? JeDEM. 3(1), 2011 , 70-79.

[38]. K. Subrahmanyama, S.M. Reich, N. Waechter and G. Espinoza. Online and offline social networks: Use of social networking sites by emerging adults. Journal of Applied Developmental Psychology. 29, 2008, 420-433.

[39]. Williams and M. Merten. A review of online social networking profiles by adolescents: implications for future research and intervention. Adolescence. 43(170), 2008, 253-274.

[40]. Y. Zhang. College students' uses and perceptions of social networking sites for health and wellness information. In Information Research. 17(3), 2011. 